Article

\title{
Evaluation of Stiffness and Dynamic Properties of a Mine Shaft Steelwork Structure through In Situ Tests and Numerical Simulations
}

\author{
Jacek Jakubowski *(D) and Przemysław Fiołek
}

Citation: Jakubowski, J.; Fiołek, P. Evaluation of Stiffness and Dynamic Properties of a Mine Shaft Steelwork Structure through In Situ Tests and Numerical Simulations. Energies 2021 14, 664. https://doi.org/10.3390/ en14030664

Academic Editor: Dariusz Prostański Received: 23 December 2020

Accepted: 26 January 2021

Published: 28 January 2021

Publisher's Note: MDPI stays neutral with regard to jurisdictional claims in published maps and institutional affiliations.

Copyright: (c) 2021 by the authors. Licensee MDPI, Basel, Switzerland. This article is an open access article distributed under the terms and conditions of the Creative Commons Attribution (CC BY) license (https:/ / creativecommons.org/licenses/by/ $4.0 /)$.
Department of Geomechanics, Civil Engineering and Geotechnics, AGH University of Science and Technology, 30-059 Krakow, Poland; pfiolek@agh.edu.pl

* Correspondence: jakubjac@agh.edu.pl

\begin{abstract}
A mine shaft steelwork is a three-dimensional frame that directs the vertical motion of conveyances in mine shafts. Here, we conduct field and numerical investigations on the stiffness and dynamic properties of these structures. Based on the design documentation of the shaft, materials data, and site inspection, the steelwork's finite element model, featuring material and geometric non-linearities, was developed in Abaqus. Static load tests of steelwork were carried out in an underground mine shaft. Numerical simulations reflecting the load test conditions showed strong agreement with the in situ measurements. The validated numerical model was used to assess the dynamic characteristics of the structure. Dynamic linear and non-linear analyses delivered the natural frequencies, mode shapes, and structural response to dynamic loads. The current practices and regulations regarding shaft steelwork design and maintenance do not account for the stiffness of guide-to-bunton connections and disregard dynamic factors. Our experimental and numerical investigations show that these connections provide considerable stiffness, which leads to the redistribution and reduction in bending moments and increased stiffness of the construction. The results also show a high dynamic amplification factor. The omission of these features implicates an incorrect assessment of the design loads and can lead to over- or under-sized structures and ultimately to shortened design working life or failure.
\end{abstract}

Keywords: shaft steelwork; finite element simulation; dynamic analysis; in situ testing; steel structure; underground construction; mine shaft; vertical transport

\section{Introduction}

A good modeling practice requires that the numerical models of structural mechanics, specifically the idealizations of member connections and stiffness of structures, are validated by in situ or laboratory tests. Lee and McClure [1] validated a three-dimensional truss model of a lattice tower based on the results of full-scaled bending and flexure-torsion tests. This model accounts for the torsional deformation of the tower truss and the stiffness of the bonds, which are usually omitted from the calculation procedure. Szafran et al. [2] used a numerical model, constructed and validated with in situ tests, to investigate the response of a tower structure to randomly generated wind loads, accounting for the dynamic response of the structure. Reliability analysis using first-order and second-order reliability methods was performed. Blum and Rasmussen presented their research on the stiffness of connections in portal frames [3], in which they investigated frames consisting of double-channel sections joined by bolted connections and angles. They found a significant influence of knee brace-to-column connection stiffness on the distribution of cross-section forces.

The results of laboratory and numerical investigations of dynamic response of beams to the impact of falling mass were carried out by D'Antimo et al. [4]. They demonstrated the suitability of calculations for the purpose of estimating the dynamic characteristics of a steel structure. Static and dynamic field tests of the response of corrugated steel plate culvert 
structures were presented by Beden [5]. Following field tests, he determined the dynamic amplification factor (DAF) on the basis of displacement and deformation measurements, showing that its value is determined by the culvert width and vehicle speed. In a numerical study of the DAF for steel box girders by Rahbar-Ranji [6], numerical simulations for different velocities and accelerations showed the dynamic factor for these structures and that the DAF takes relatively high values in the range of low lifting velocities, which is not accounted for by local regulations. Parida and Talukdar [7] carried out research on the DAF in steel truss girder bridges, analyzing the influence of span length, traffic speed and volume, and technical condition of the bridge on the dynamic factor value. They found that the dynamic factor depends on movement conditions and that it reaches different values for different elements of a girder.

Khan and Krige [8] investigated the structural integrity of shaft steelwork in the context of South African shafts. They accounted for the impact of structural weakness resulting from corrosion in steelwork elements. Experimental research on the load-carrying capacity of shaft guides was conducted by Fiołek and Jakubowski [9] and Fiołek et al. [10]. They showed that high corrosion loss reduces the resistance to local buckling of hotrolled profiles. They demonstrated the suitability of the finite element (FE) computational approach and Eurocode 3 procedures for assessing the load-carrying capacity of the guides, even in a state of high corrosion loss.

Lateral movements of mine conveyances induce forces acting on steelwork structures. These movements are caused by misaligned guidelines and non-uniform mass distribution in the conveyance, resulting in forces at the contact between the conveyance guide rollers or shoes and the guide. Heyns and Heyns [11] presented research on guide loads based on dynamic conveyance-steelwork models. They proposed a 3D conveyance model consisting of mass and the moment of inertia with six degrees of freedom. The interaction between the conveyance and the guide was modelled with elastic constraints. The guide was represented by beam finite elements, while the buntons were represented by truss elements with one degree of freedom. A dynamic model of a conveyance that incorporated the mass and moment of inertia was presented by Xing-Ming et al. [12]. The guide roller was represented by a parallel-connected elastic element and a viscous damper element. The dynamic model was used to assess conveyance vibrations caused by the three most common types of guideline damage. The data obtained from the model and the results of vibration measurements showed strong agreement. A method of detecting failures of guide rail according to multi-time scale and dynamic time warping was present by Wu et al. [13]. They analyzed the vibration signal under three types of guide failure and showed high accuracy of the method. It has been observed that guide misalignments affect guide loads. Wolny and Matachowski [14] made an effort to assess guide load forces based on misalignment measurements. They presented a 3D shell and beam FE model of skip to estimate forces and stresses in the loaded conveyance components. They measured strains to validate the numerical simulation and their results of the simulation and measurements were consistent in terms of guide loads. They noticed major discrepancies in skip deformations and stresses and explained them by differences between the model and the actual skip construction. Despite the apparent theoretical description of the conveyance-steelwork system behavior, the diversity and complexity of causal effects and interactions make the assessment of forces with theoretical models inaccurate [15].

The current routines and regulations for shaft steelwork design in South Africa, Australia, New Zealand and Poland [16-18] consider the connections between the guide and the bunton to be pinned. This is a conservative approach that leads to oversimplified calculations and increased design loads and displacements. Such safe approximation may be seen as justified by the expected degradation of the connections as a result of increased corrosion in the shaft. However, it is not supported by any research known to the authors. The existing literature lacks research on the stiffness of connections of shaft guides, either new or corroded under shaft conditions. This deficiency of research precludes an accurate assessment of the actual connection rigidity and distribution of cross-sectional forces along 
the guide axis. It also prevents the correct calculation of the steelwork response to dynamic loads. The aim of this study was to fill these gaps and examine the stiffness of the shaft steelwork, the actual support conditions of guides, and the dynamic characteristics of the steelwork structure. As part of the research program, load tests of the steelwork were performed in shafts, numerical FE models were built and validated, and a series of linear and non-linear static and dynamic simulations were performed.

\section{Shaft Steelwork Stiffness}

\subsection{In Situ Load Test of the Structure}

Shaft steelwork directs the linear motion of mine conveyances in vertical shafts. Cages and skips $20-80 \mathrm{Mg}$ in total mass move along the guides at $20-60 \mathrm{~km} / \mathrm{h}$. The main shaft steelwork components in Silesian hard coal mines include main and secondary buntons mounted horizontally and guides mounted to buntons vertically. Figure 1 shows a simplified steelwork visualization.

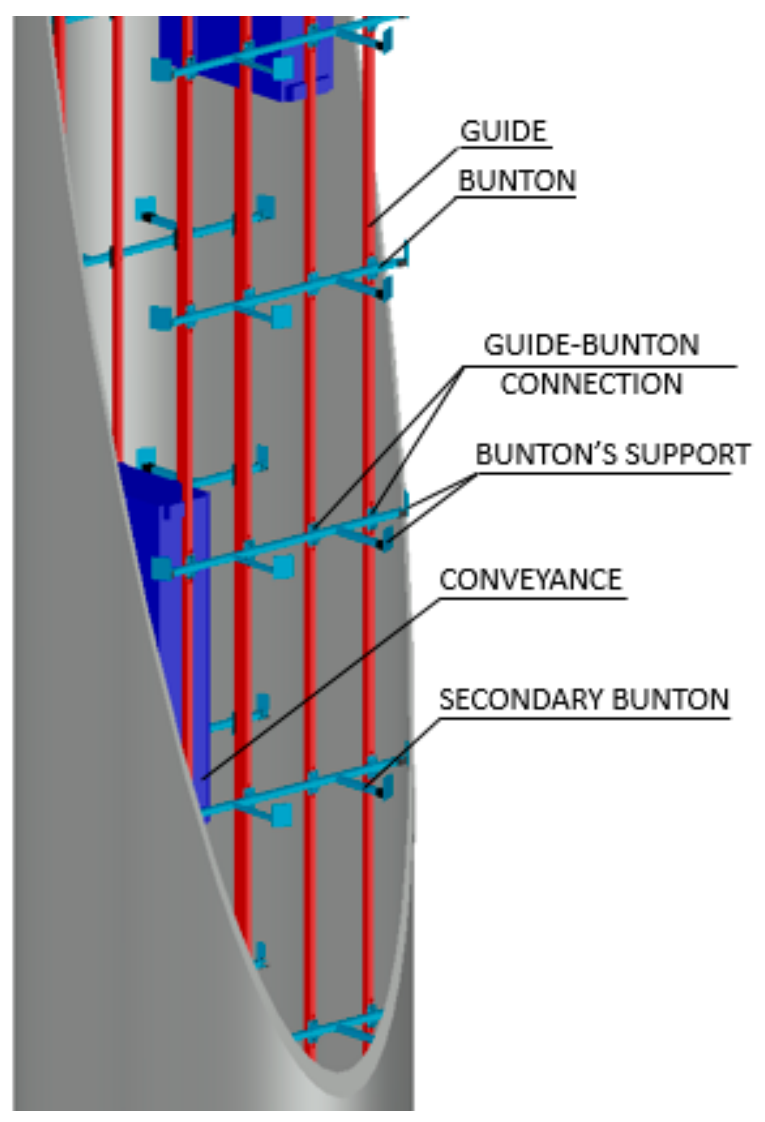

Figure 1. Approximate visualization of a shaft steelwork.

Bolted connections are used to connect the members in the structure. Buntons are fixed by short cast iron or steel brackets anchored in the shaft's concrete lining. Horizontal buntons are configured $4.5 \mathrm{~m}$ apart along the shaft axis. Each guide segment is $9 \mathrm{~m}$ long and is fixed to three buntons. This system may, therefore, be considered a 3D frame made of hot-rolled sections jointed with bolted connections and loaded with forces from the impact of conveyance guides.

As part of the field tests, a load test was applied to one of the Upper Silesian hard coal mine shafts. The guides in the examined shaft were made of standard European channels, while the buntons were of equal angles. The cross-section of the guides and buntons is given in Figure 2. The guide was connected to the bunton with bolts. Figure 3 shows two types of these connections. 


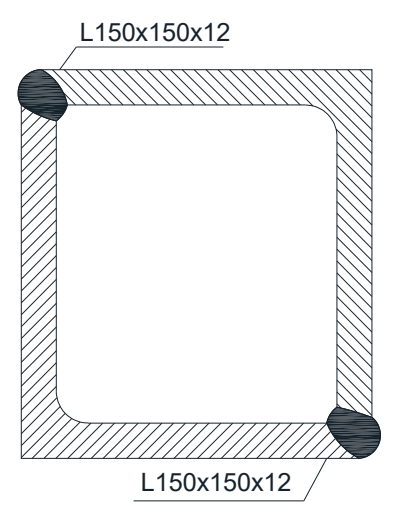

(a)

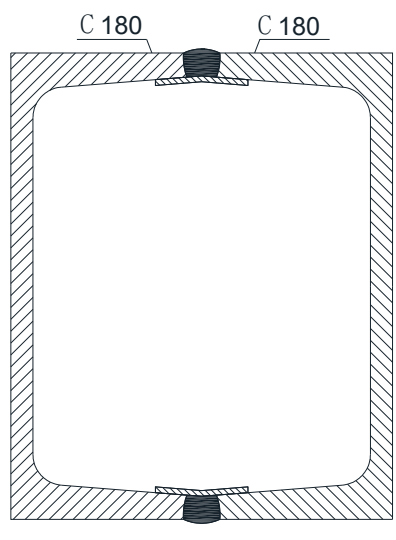

(b)

Figure 2. Cross-section of the (a) bunton and (b) guide in the examined shaft.

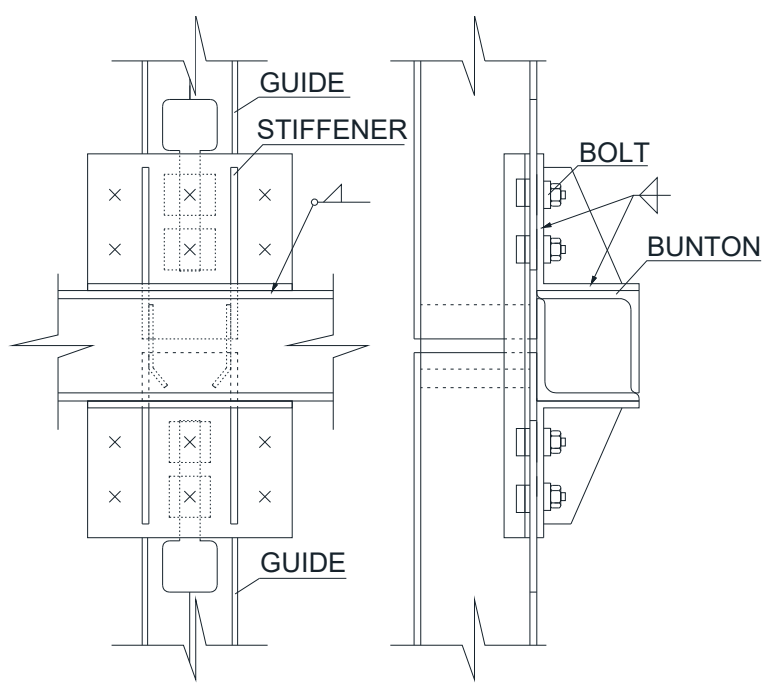

(a)

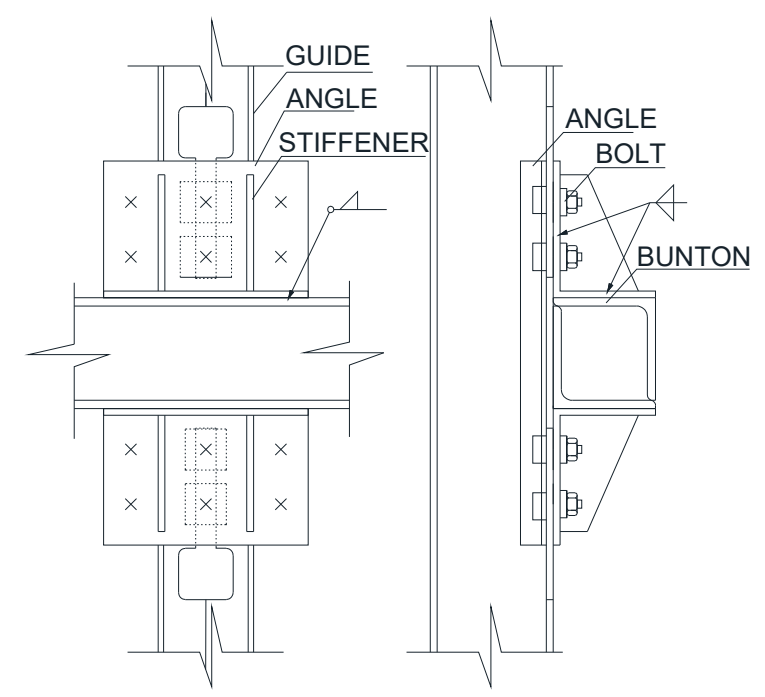

(b)

Figure 3. Guide-to-bunton connections (a) reaching two adjacent guides and (b) in the middle of a guide.

The shaft we examined was a two-compartment shaft used for mine output and staff transport with four four-deck cages. Figure 4 presents a photo taken by the authors on the cage top transom showing the connection between the guide and the bunton as well as the guide roller, through which the carried load interacts with the guide.

The stiffness of the connections was tested directly in a shaft $850 \mathrm{~m}$ deep. Two series of measurements for each diagram were carried out in arbitrary locations at depths of $150 \mathrm{~m}$ (series 1) and $450 \mathrm{~m}$ (series 2). The thickness of the walls of the steelwork members was measured with a PosiTector ultrasonic thickness gauge manufactured by DeFelsko (Ogdensburg, NY, United States). The thickness was close to the nominal value and did not indicate any considerable corrosion.

The procedure we followed for the in situ load tests is shown in Figure 5. Briefly, the guide was statically loaded with a chain hoist. The force applied to the guide was measured with a dynamometer; the displacement near the point of force application and rotation angles near the connection between the bunton and the guide were measured with a displacement gauge and inclinometers. The guide displacement measurements were taken with dial sensors manufactured by Mitutoyo (Kawasaki, Japan) with an accuracy of $10^{-2} \mathrm{~mm}$. The bunton displacement measurement was taken with a laser distance sensor 
manufactured by Baumer (Friedberg, Germany) with an accuracy of $10^{-3} \mathrm{~mm}$. The rotation angles were measured with Tuff Tilt inclinometers manufactured by Jewell Instruments (Manchester, United Kingdom) with an accuracy of $6 \cdot 10^{-4}$ degrees.

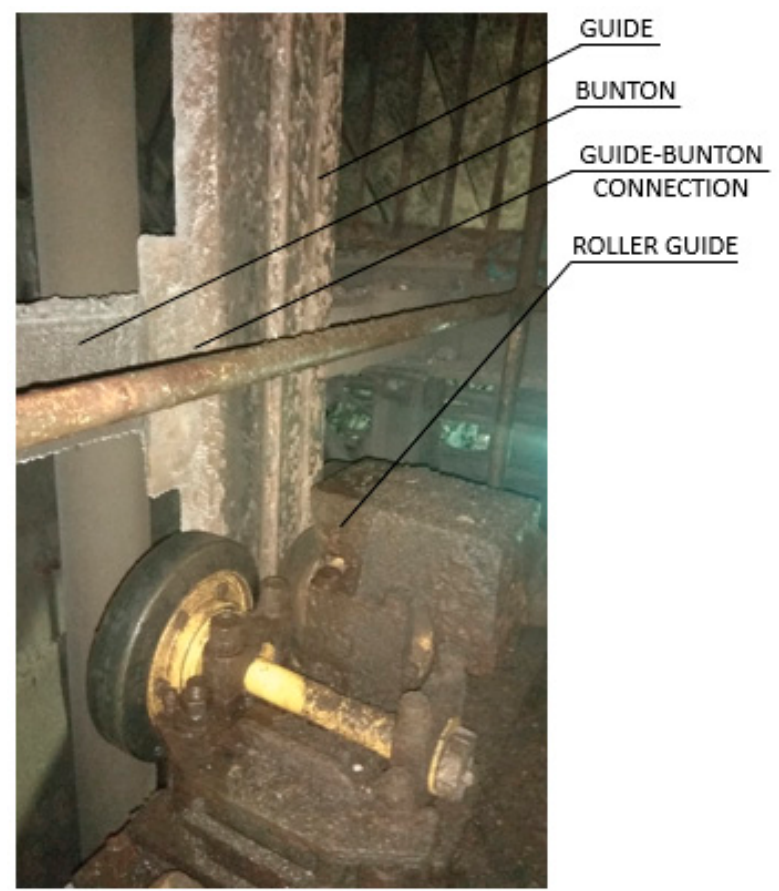

Figure 4. Connection between the guide and the bunton and guide roller.

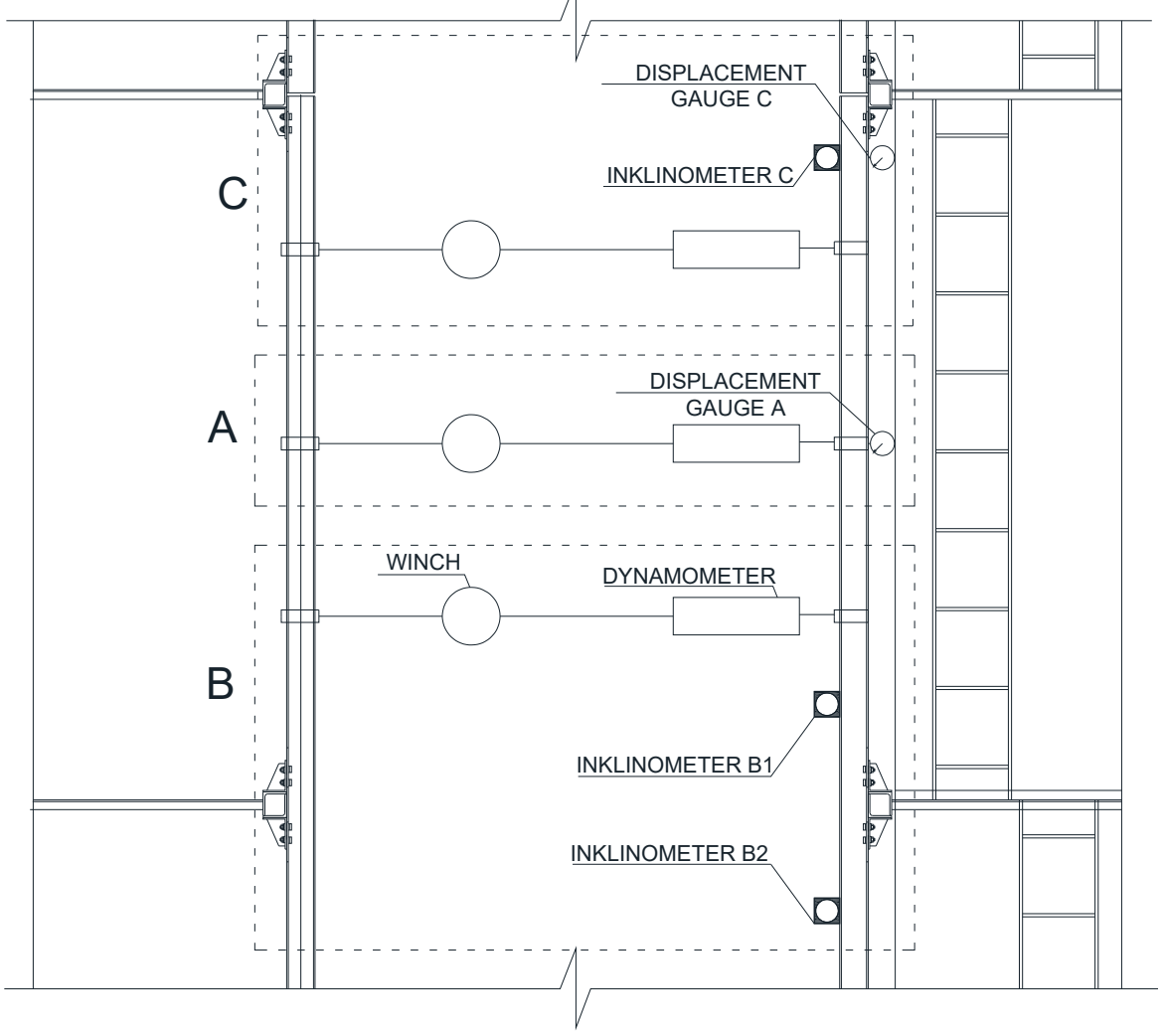

Figure 5. The three load schemes (A, B, and C) used for the field tests. 
The displacement measurements were taken for three force application points in three schemes (Figure 5) to provide comprehensive data on the guide's deformability. For scheme A, the force was applied to the mid-point between the buntons, and we measured the displacement of the guide in the loaded section. For scheme B, the force was applied $1.5 \mathrm{~m}$ from the bunton axis towards the guide-bunton connection at the mid-point of the guide. The measured values included guide rotation angles on both connection sides at a distance of $60 \mathrm{~cm}$ from the bunton axis. For scheme $C$, the force was applied $1.5 \mathrm{~m}$ from the bunton axis towards the guide-bunton connection at the end of the guide. The measured values included the rotation angle of the guide section at a distance of $60 \mathrm{~cm}$ from the bunton axis and the corresponding vertical displacement. For schemes $B$ and $C$, the bunton axis displacement in the direction of the force application was also measured.

\subsection{Finite Element Model of the Steelwork Structure}

A FE model of the steelwork structure was developed in Abaqus 6.12 based on the design documentation and site visits. In Polish mines, steelwork geometry is regularly monitored by staff and external inspections $[18,19]$. The geometry of a repeatable steelwork segment was considered, including three main buntons, to which four $9 \mathrm{~m}$ guides and secondary buntons were mounted. The sections of the steelwork were represented by four-node shell elements with reduced integration (S4R) [20]. Elastic constants for steel were adopted following EC3 [21], specifically Young's modulus E = 210 GP and Poisson's ratio $v=0.3$. Due to the potentially large displacements and deformations, a geometric non-linear analysis was performed. Although the components were not expected to yield, this possibility could not be ruled out, so material nonlinearity was introduced. Steel was reproduced using an elastic-perfectly plastic (bilinear) model based on the HMH yield criterion. A yield strength of $355 \mathrm{MPa}$ was adopted according to EC3 for the steel grade from which the steelwork was constructed. Boundary conditions reflected the conditions of the in situ load tests, as described in Section 2.1. Figure 6 provides the details regarding the connection between the bunton and the guide, and Figure 7 shows views of the model. Table 1 lists the geometrical features of the steelwork structure's components represented in the model.

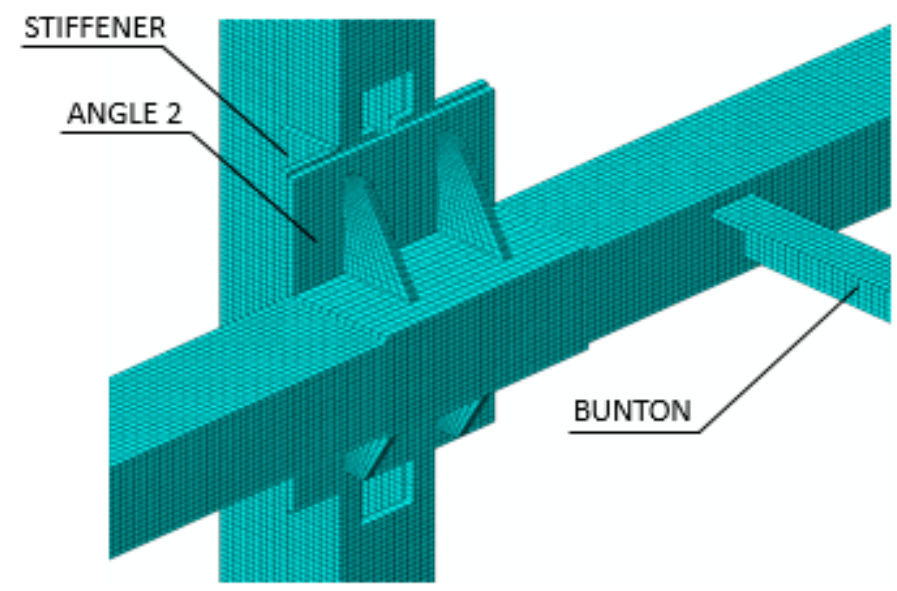

(a)

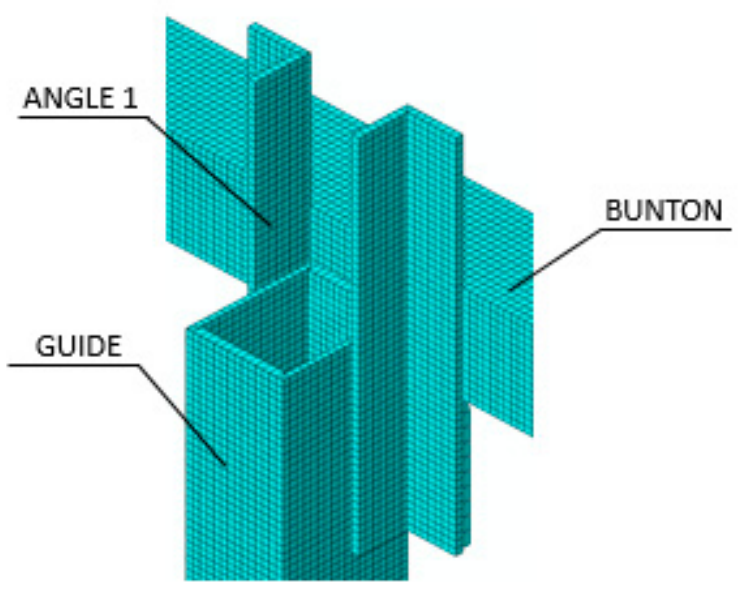

(b)

Figure 6. View of the guide-to-bunton connections model: (a) joint at mid-point of guide; (b) joint at the end of the guide. 


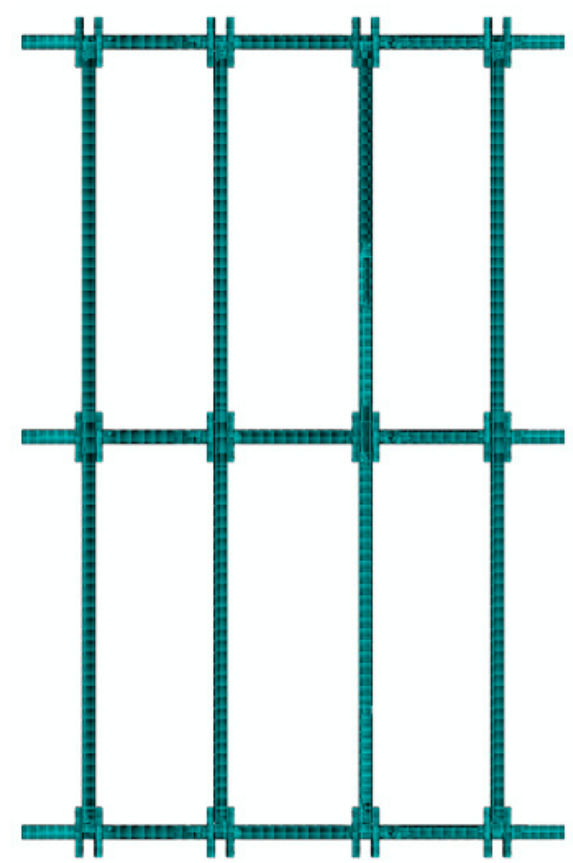

(a)

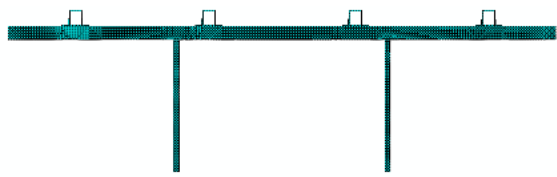

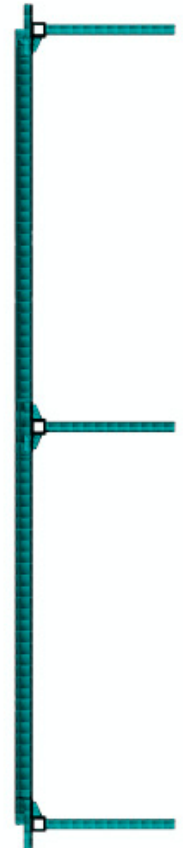

(b)

(c)

Figure 7. Views of the model from the (a) front, (b) side, and (c) top.

Table 1. Geometry of model components.

\begin{tabular}{cccc}
\hline Component & Section & $\begin{array}{c}\text { Transverse } \\
\text { Dimensions }(\mathbf{m m})\end{array}$ & Wall Thickness (mm) \\
\hline Guide & $2 \times \mathrm{C} 180$ & $180 \times 140$ & 8 and 13 \\
Bunton & $2 \times \mathrm{L} 150 \times 150 \times 12$ & $162 \times 150$ & 12 \\
Secondary bunton & $\mathrm{L} 60 \times 100 \times 10$ & $60 \times 100$ & 10 \\
Angle 1 & $\mathrm{L} 80 \times 80 \times 10$ & $80 \times 80$ & 10 \\
Angle 2 & $\mathrm{L} 200 \times 150 \times 10$ & $200 \times 150$ & 10 \\
Stiffener & PL10 & $170 \times 115$ & 10 \\
\hline
\end{tabular}

The spacing and diameter of holes and the dimensions of bolts can have a considerable impact on results for the load-carrying capacity if a connection failure is observed. However, the purpose of the model applied and presented here was to reflect connection stiffness only. The direct representation of a connection by modelling detailed geometry of bolts and welds would be pointless and make the model unnecessarily complex. Therefore, simplified interactions between the nodes of the components to be joined were applied. For welded joints, no displacements and rotations of connected nodes in the weld were allowed (tie constraint). For bolted connections, relative displacements of the nodes of the connected components were limited (pin constraint). The free ends of the buntons were fixed, which corresponds to their being fixed in cast iron brackets anchored to the shaft support. Hard contacts and a friction coefficient of 0.2 were introduced between the surfaces of the sections forming a bond [22-24]. The model was loaded with forces acting along a line of winch and dynamometer, in accordance with the in situ testing schemes (Figure 5). 
Six load simulations were carried out in Abaqus following the field-testing diagram. They facilitated the estimation of displacement and rotations values in the model corresponding to the measurements recorded during shaft tests. The static, geometric, and material nonlinear FE analysis was employed.

\subsection{Comparison of Field and Numerical Test Results}

To compare the results of simulations and field measurements, the force vs. horizontal displacement and force vs. cross-section rotation characteristics were plotted for six load cases (load cases A, B, and C for each of the two series). Figure 8 shows the force vs. horizontal displacement graphs for tests and simulations in scheme A. Figure 9 shows the force vs. rotation characteristics on both sides of the half-length guide connection to buntons according to test scheme B. Both simulation results and in situ measurements are presented. Figure 10 shows the force vs. rotation and force vs. displacement characteristics according to test scheme $\mathrm{C}$ measurements and simulations.

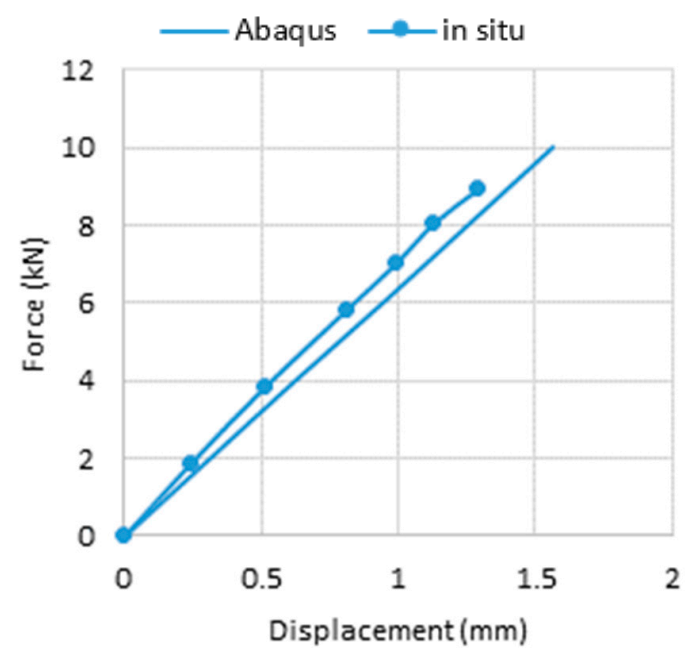

(a)

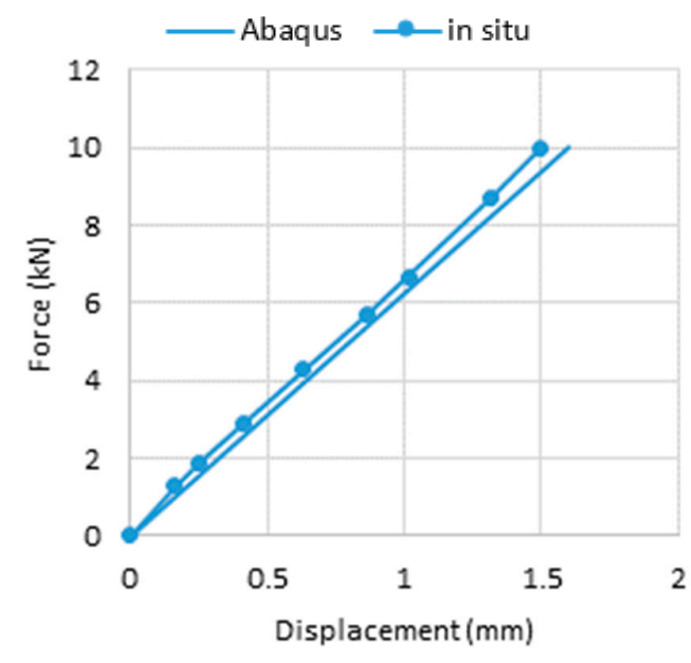

(b)

Figure 8. Scheme A measurements and simulation results for (a) Series 1 and (b) Series 2.

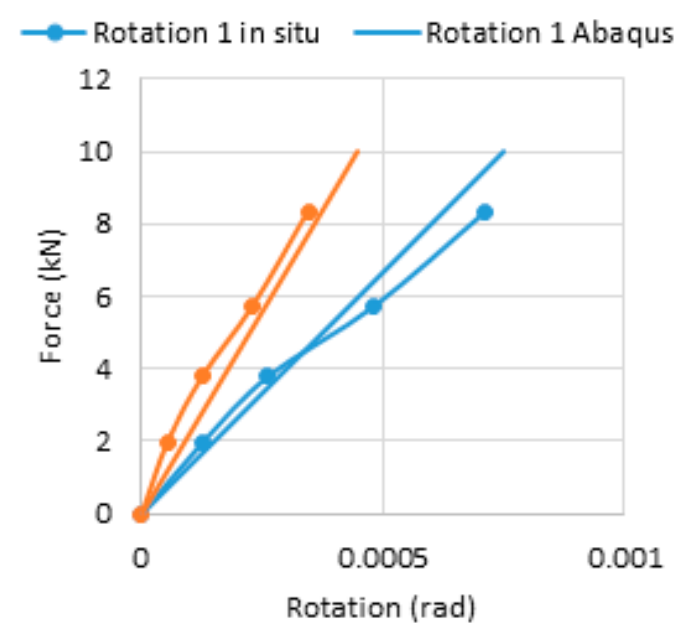

(a)

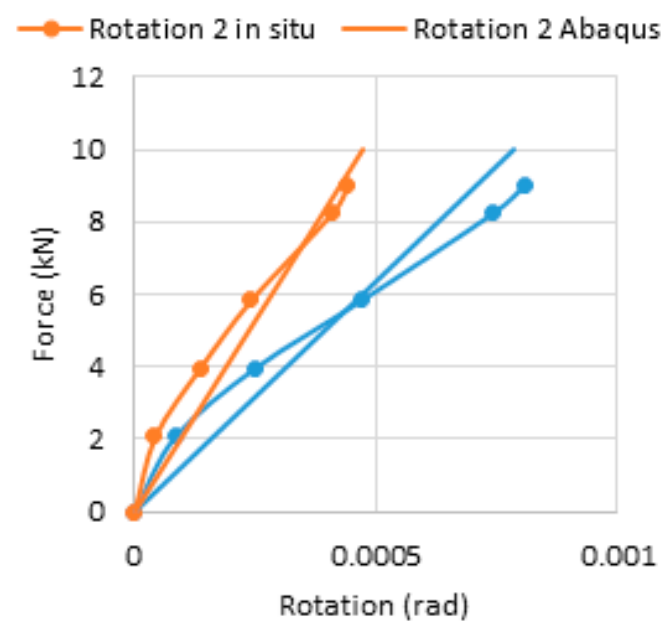

(b)

Figure 9. Scheme B measurement and simulation results for (a) Series 1 and (b) Series 2. Rotation 1-measurement using inclinometer B1; Rotation 2-measurement using inclinometer B2. 


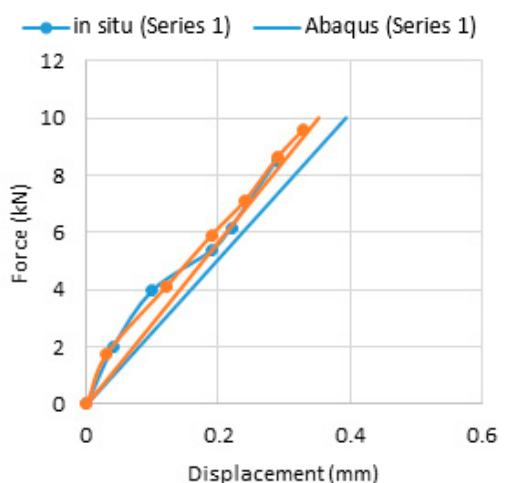

(a)

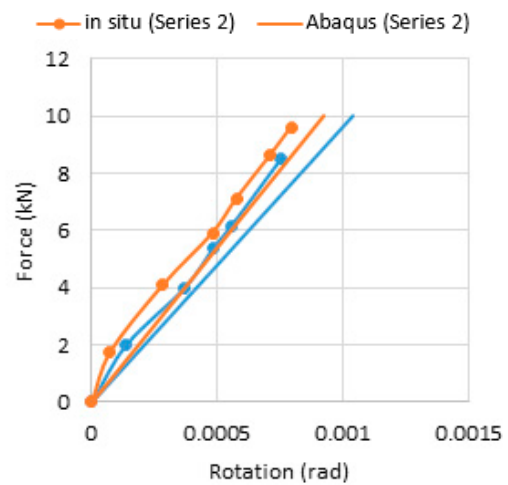

(b)

Figure 10. Test scheme $C$ results for (a) force vs. displacement and (b) force vs. rotation.

A comparison of measurements in the shaft and numerical simulations indicates strong agreement between the obtained results. Deformation characteristics for in situ testing show small variations around the linear trend, which may be explained by clearance levelling in the dynamometer and bolted connections but have a negligible impact on the results of the simulation. Displacement and rotation characteristics show strong agreement between experimental and model characteristics, which indicates that the model properly reflects the structure's stiffness and response to loads.

\section{Finite Element Dynamic Analysis}

\subsection{Modal Analysis}

The conveyance loads the guides through wheels of guide rollers or through slipper plates of guide shoes. In both cases, these loads are dynamic, but they are higher for slipper plates. For this reason, the FE Abaqus model, previously validated via in situ testing, was used to conduct a series of numerical simulations of the structure's response to dynamic loads through the slipper plates. The direction of guide loads was perpendicular to the guides. A force that acts perpendicular to the bunton (in the $\mathrm{Z}$ direction; see Figure 11) is the "face force", while a force that acts parallel to the bunton (in the X direction) is a "side force".

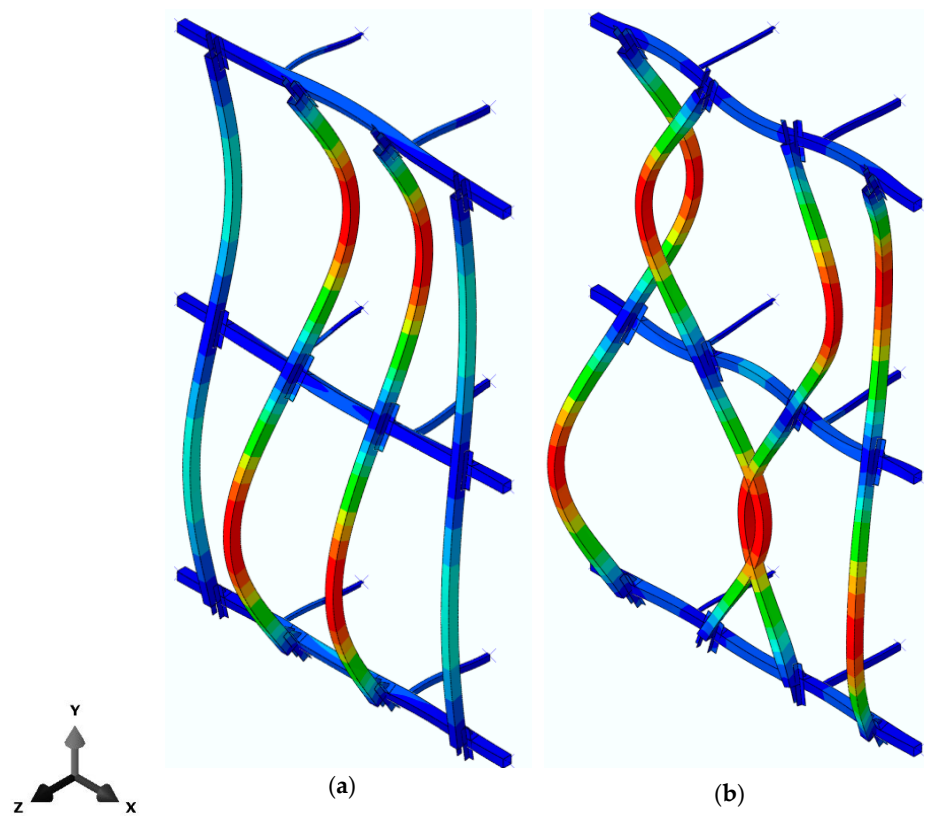

Figure 11. The second (a) and fourth (b) natural mode shapes. Colors indicate the displacement magnitude. 
We conducted a linear modal analysis and computed the first ten natural modes of the steelwork structure. Vibration in the Y direction (parallel to the guide axis) was dominant for the first and third natural modes. Face force direction corresponds to the second mode and side force direction corresponds to the fourth mode vibrations. The second and fourth natural frequencies of 31 and $35 \mathrm{~Hz}$, respectively, are high and practically preclude the resonance of the steelwork structure. The respective mode shapes are shown in Figure 11.

\subsection{Nonlinear Dynamic Analysis}

The second stage of the dynamic analysis was the simulation of the structure's response to dynamic loads caused by conveyance mass impacts. A $10 \mathrm{kN}$ square-wave force pulse was applied to the model of the structure, which corresponds to the average value of the guide loads in the shaft. Two load cases were considered, corresponding to a face force acting along the $\mathrm{Z}$ direction (Figure 12a) and a side force acting along the $\mathrm{X}$ direction (Figure 12b). Loads were applied to the guide halfway between the buntons (fixing points), as here, they generate the greatest bending moments and deformations in the guide, thus being the most vulnerable position in terms of structure safety. To prevent the modeling effects of point force representation, i.e., artificial local stress concentrations and torsional moments, the force was applied through two section walls (Figure 12).

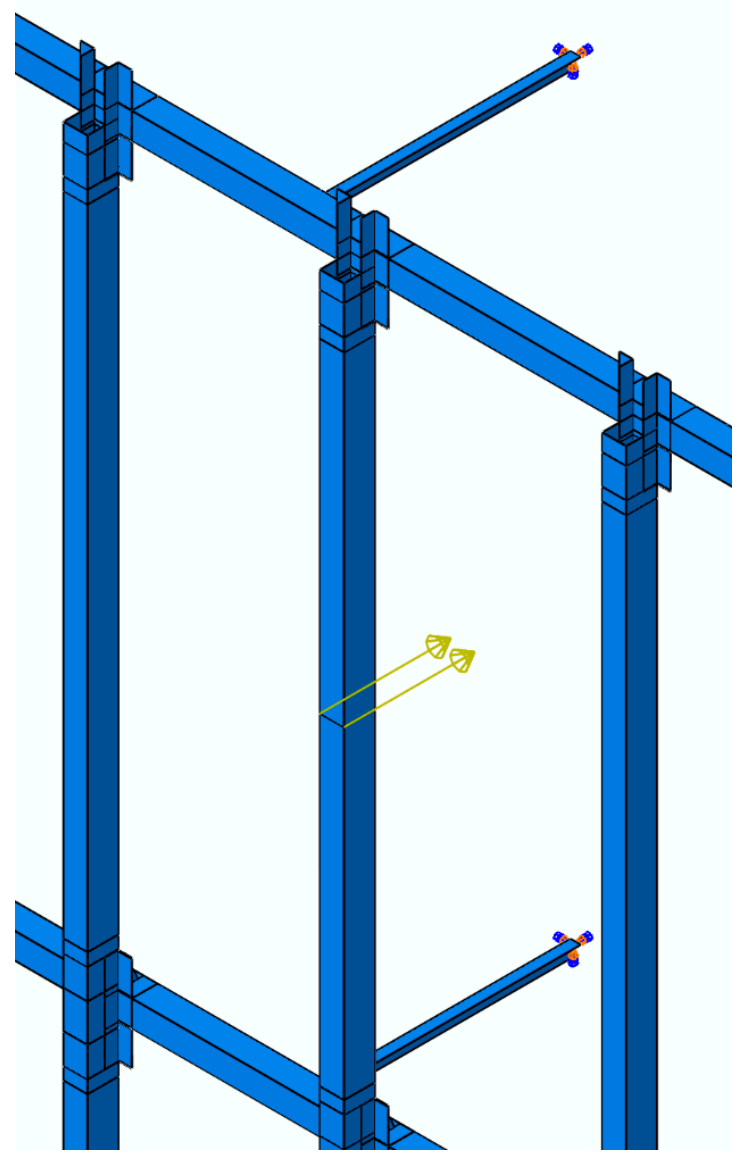

(a)

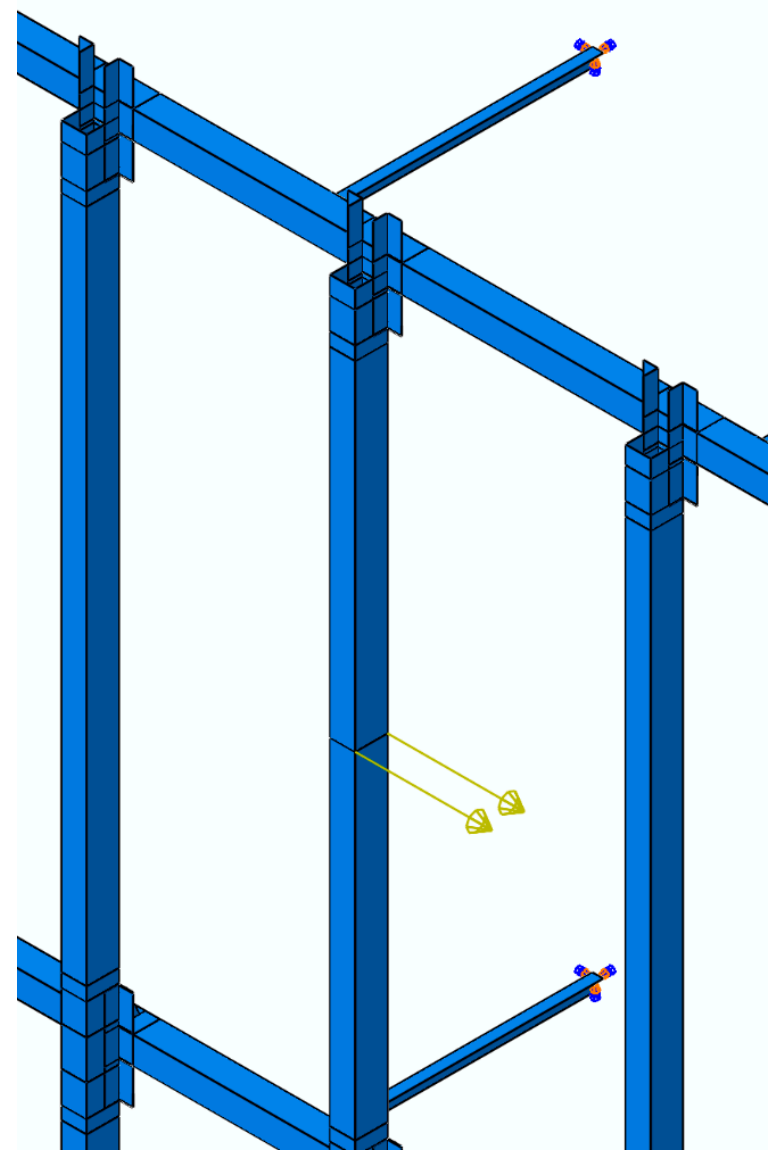

(b)

Figure 12. Structure model, support, and loads: (a) applying face force; (b) applying side force.

The action of the conveyance on the guide can be considered a force pulse. As the existing literature lacks data concerning its shape, the least favorable variant, i.e., a squarewave pulse, was chosen. The length of the force pulse corresponds to the time during which the guide roller or shoe is in contact with the guide. On the basis of the performed force measurements, we estimated that the time during which the skip was in contact with the 
guide was between 0.05 and 1.0 natural periods of the steelwork structure. To determine the effect of the force pulse length on the maximum displacement, a series of simulations for face and side loads was performed with the pulse duration ranging between 0.1 and 1.0 natural periods. These simulations showed that the amplitude increases with the pulse duration between 0.1 and 0.4 natural periods (Figures 13 and 14). For a longer force pulse, no further increase in amplitude was observed.

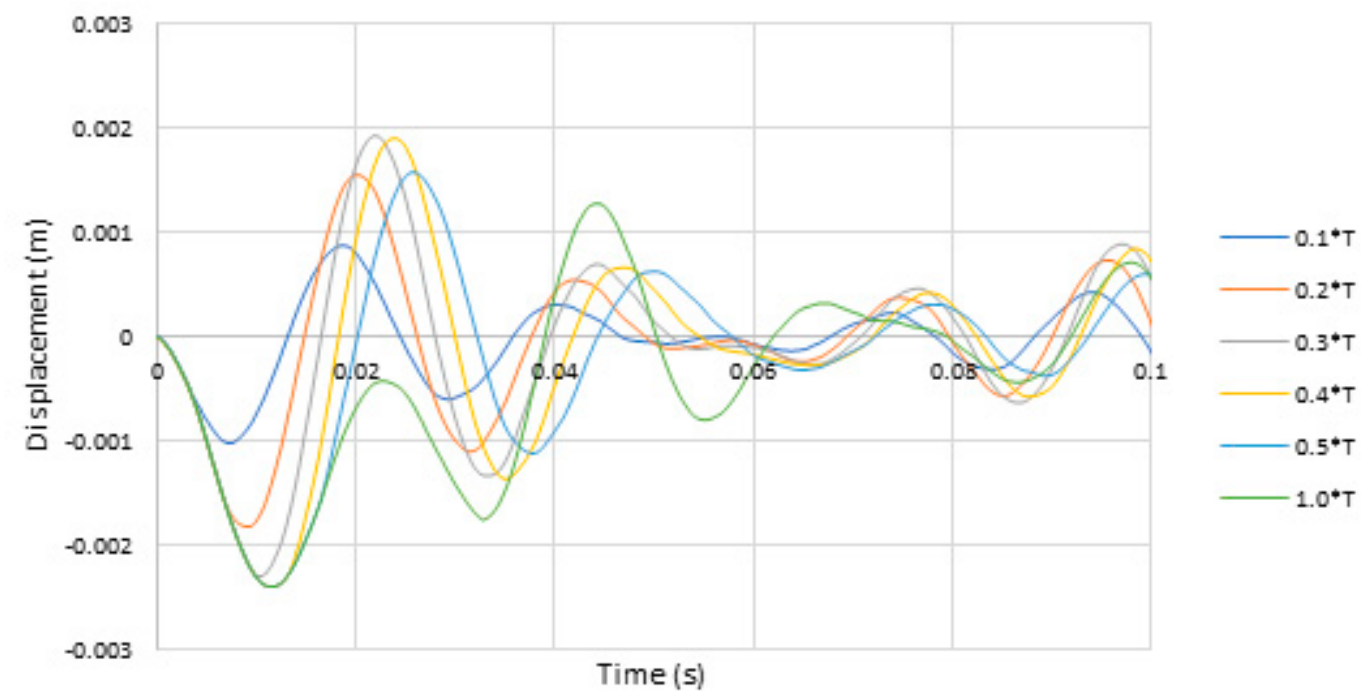

Figure 13. Vibration of loaded section under face force. Simulation results.

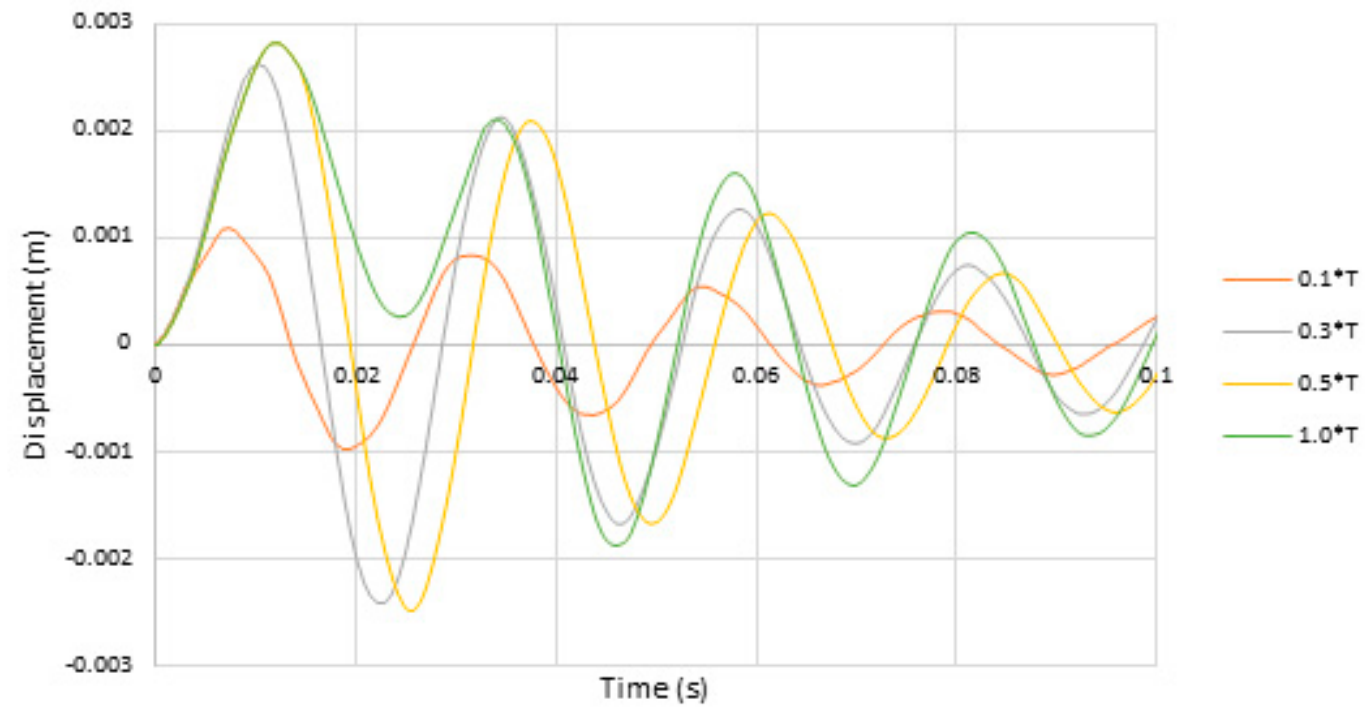

Figure 14. Vibration of loaded section under side force. Simulation results.

A static analysis was also performed for the load schemes shown in Figure 12 and force values as in the dynamic analyses. The dynamic response of the steelwork structure to the guide load was characterized by the dynamic amplification factor, calculated by

$$
\mathrm{DAF}=u_{d y n} / u_{s t a}
$$

where $u_{d y n}$ is the maximum displacement under dynamic load, and $u_{s t a}$ is the displacement under a static load. The value of the dynamic DAF reached 1.90 for face force and 1.89 for side force. As expected, the dynamic analysis of shaft steelwork and DAF assess- 
ment showed to be insensitive to the damping coefficient within the range of its realistic values [7,25-27].

\section{Discussion}

The steelwork load tests we carried out in the mine shaft showed that connections exhibited considerable stiffness. There are strong grounds to represent the bunton-to-guide joints in design and maintenance models as semi-rigid connections. However, current design practices and standards [16-18] treat the guide-to-bunton connections as pinned. This leads to simplified calculations and increased design bending moments (over a third increase for the considered steelwork). This practice may be justified by the assumption that the connections degrade due to corrosion. However, to the best of our knowledge, no other studies have attempted to determine the effect of corrosion on the stiffness of these connections. Design procedures take the corrosion effect into account by assuming a corrosion allowance for guides and buntons. A further reduction in structure stiffness due to the same phenomenon may be redundant. Daily visual check-ups of the shaft, as well as legally required periodic inspections, aim to maintain the steelwork, including its connections, in good condition. Taking the stiffness of connections into account leads to reduced design bending moment and guide displacements, resulting in reduced thickness of designed walls or longer design working life, despite corrosion loss of the profiles. Nowadays, it does not make the design computations inadequately complex when using the available tools for structural analysis.

The FE model used for numerical analysis was built on the basis of design documentation of the shaft, materials data, and site inspection. Test loads of the structure carried out in the shaft allowed us to validate this model and the applied simplifications. The comparison of measurements in the shaft and FE simulation results shown in Section 2.3 indicated a strong agreement between the behavior predicted by the model and that of the structure.

Within the analyzed load range, the guide-to-bunton connections showed linear force-rotation and force-displacement relationships. Some minor nonlinearities for in situ testing were observed, but the general linear tendency was clear and aligned with the model's response.

The modal analysis provided information concerning the natural frequencies and mode shapes. The high natural frequencies (31 and $35 \mathrm{~Hz}$ ) indicated the considerable stiffness of the structure compared to other hot-rolled profile constructions, which are usually characterized by a greater span of elements (e.g., four times greater for typical industrial facilities) at a similar bending stiffness. Batko and Korbiel $[25,26]$ conducted an experimental modal analysis in a copper mine shaft where the span of guides between the buntons was $1.5 \mathrm{~m}$, and the first natural frequency of the shaft steelwork measured in such conditions was less than $80 \mathrm{~Hz}[25,26]$. Given the difference in stiffness stemming from a smaller bunton span and profile, this value is consistent with the values obtained via the numerical simulation presented here.

The value of the dynamic DAF (1.90 for face force and 1.89 for side force) corresponds to the conveyance-guide interaction mode, similar to the one provided by slipper plates [16]. Under normal operation using guide rollers with shock absorbers [28-30], the force does not increase in sharp steps. However, should the guide roller fail, their task is taken over by the steel slipper plates. For roller guiding, which dominates in Polish mines, this condition corresponds to emergency operation; however, in practice, it occurs fairly often and can last for a long duration.

Our results indicate that carrying out non-routine tests and analyses of the shaft steelwork enables significantly more accurate representations of the behavior of the shaft steelwork structure. Enhanced assessment of the structure behavior reduces uncertainty in the design load, thus improving the reliability and safety of structures.

Further research will be carried out to quantify the effect of corrosion loss on the capacity of shaft steelwork guides and buntons, loads, and reliability of steelwork structures. 


\section{Conclusions}

Here, we presented novel experimental and numerical investigations of the stiffness and dynamics of a mine shaft steelwork structure. Stiffness was tested under mining conditions by applying a static load to the structure and measuring deformations. Our tests indicated that the guide-to-bunton connections exhibit considerable stiffness and can be treated as semi-rigid joints. The FE numerical model built on the basis of collected data concerning the structure, geometry, and material of steelwork was successfully validated based on the results of in situ tests of structure behavior. Using linear modal analysis, the natural frequencies and mode shapes of the steelwork structure were calculated as 31 and $35 \mathrm{~Hz}$ in the face force and side force directions, respectively. Non-linear dynamic and static FE analyses indicated high dynamic amplification factor values. The current practice and regulations of shaft steelwork design consider joints as pinned, do not take their stiffness into account, and disregard dynamic factors. Our tests and simulations indicate that the omission of these features in the design model results in the incorrect assessment of the design load and ultimately over- or under-sized structures. This can lead to shortened design working life or failure.

Author Contributions: Conceptualization, J.J. and P.F.; methodology, J.J. and P.F.; formal analysis, J.J. and P.F.; investigation, J.J. and P.F.; writing, J.J. and P.F. All authors have read and agreed to the published version of the manuscript.

Funding: This research received no external funding.

Institutional Review Board Statement: Not applicable.

Informed Consent Statement: Not applicable.

Data Availability Statement: Data is contained within the article.

Conflicts of Interest: The authors declare no conflict of interest.

\section{References}

1. Lee, P.-S.; McClure, G. Elastoplastic large deformation analysis of a lattice steel tower structure and comparison with full-scale tests. J. Constr. Steel Res. 2007, 63, 709-717. [CrossRef]

2. Szafran, J.; Juszczyk, K.; Kamiński, M. Experiment-based reliability analysis of structural joints in a steel lattice tower. J. Constr. Steel Res. 2019, 54, 278-292. [CrossRef]

3. Blum, H.B.; Rasmussen, K.J.R. Experimental and numerical study of connection effects in long-span cold-formed steel double channel portal frames. J. Constr. Steel Res. 2019, 155, 480-491. [CrossRef]

4. D'Antimo, M.; Latour, M.; Rizzano, G.; Demonceau, J.F. Experimental and numerical assessment of steel beams under impact loadings. J. Constr. Steel Res. 2019, 158, 230-247. [CrossRef]

5. Beden, D. Dynamic amplification factors of corrugated steel plate culverts. Eng. Struct. 2013, 46, 193-204.

6. Rahbar-Ranji, A. Dynamic Magnification Factor in a Box-Shape Steel Girder. J. Inst. Eng. India Ser. C 2014, 95, 11-18. [CrossRef]

7. Parida, S.; Talukdar, S. An Insight to the Dynamic Amplification Factor for Steel Truss Girder Bridge. Int. J. Steel Struct. 2020, 20, 1341-1354. [CrossRef]

8. Khan, M.M.; Krige, G.J. Evaluation of the structural integrity of aging mine shafts. Eng. Struct. 2002, 24, 901-907. [CrossRef]

9. Fiołek, P.; Jakubowski, J. Local buckling of highly corroded hot-rolled box-section beams. J. Constr. Steel Res. 2019, 157, 359-370. [CrossRef]

10. Fiołek, P.; Jakubowski, J.; Tomczak, K. Code calculations for local stability of shaft guides. Studia Geotech. Mech. 2017, 3, 11-16. [CrossRef]

11. Heyns, P.; Heyns, M. Simulation of mining conveyance dynamics. Trans. Instr. Min. Metall. 1997, 106, A77-A83.

12. Xing-Ming, X.; Zhang-Fang, L.; Jun, Z. Study on fault mechanism of shaft hoist steelwork. Procedia Earth Planet. Sci. 2009, 1, 1351-1357. [CrossRef]

13. Wu, B.; Li, W.; Jiang, F. Fault diagnosis of mine shaft guide rails using vibration signal analysis based on dynamic time warping. Symmetry 2018, 10, 500. [CrossRef]

14. Wolny, S.; Matachowski, F. Analysis of loads and stresses in structural elements. Engng. Trans. 2010, 58, 153-174.

15. Płachno, M. New approach to the design of shaft steelwork. Arch. Min. Sci. 2005, 4, 465-496.

16. SANS 10208-4:2016. Design of Structures for the Mining Industry Part 4: Shaft System Structures; SABS Standards Division: Pretoria, South Africa, 2016.

17. AS/NZS 3785.6:2015. Underground Mining—Shaft Equipment Part 6: Fixed Guides, Rope Guides and Rubbing Ropes for Conveyances; Standards Australian Limited/Standard New Zealand: Sydney, Australia, 2015. 
18. Ministry of Energy. The Decree of the Minister of Energy of 23th November 2016 on Specific Requirements for Operating Underground Well Sites; Journal of Laws of the Republic of Poland: Warszawa, Poland, 2017. (In Polish)

19. Lipecki, T.; Kim, T.T.H. The development of terrestrial laser scanning technology and its applications in mine shafts in Poland. J. Pol. Miner. Eng. Soc. 2020, 46, 301-310.

20. Dassault Systèmes Abaqus Analysis User's Manual; Dassault Systèmes Simulia Corporation: Providence, RI, USA, 2010.

21. European Committee for Standardization. EN-1993-1-1 Eurocode 3: Design of Steel Structures-Part 1-1: General Rules and Rules for Buildings; CEN: Brussel, Belgium, 2005.

22. Xu, G.; Wang, Y.; Du, Y.; Zhao, W.; Wang, L. Static strength of friction-type high-strength bolted T-stub connections under shear and compression. Appl. Sci. 2020, 10, 3600. [CrossRef]

23. Gödrich, L.; Wald, F.; Kabeláč, J.; Kuř́íková, M. Design finite element model of a bolted T-stub connection component. J. Constr. Steel Res. 2019, 157, 198-206. [CrossRef]

24. Grimsmo, E.; Aalberg, A.; Langseth, M.; Clausen, A. Failure modes of bolt and nut assemblies under tensile loading. J. Constr. Steel Res. 2016, 126, 15-25. [CrossRef]

25. Batko, W.; Korbiel, T. Shaft steelwork tests based on the global damping factor. Diagnostyka 2007, 41, 27-38. (In Polish)

26. Batko, W.; Krobiel, T. Maintenance of mining shaft reinforcement based on global damping coefficient. Maint. Reliab. 2008, 1, $44-48$.

27. Buchmann, H. Vibration Problems in Structures Practical Guidelines; Springer: Basel, Switzerland, 2011.

28. Hansel, J.; Cichociński, A.; Hansel, Z.; Płachno, M.; Rokita, T.; Skorupa, A.; Wójcik, M. New Methods of Designing Hoist Conveyances and Shaft Steelwork; AGH: Kraków, Poland, 1994. (In Polish)

29. Mazurek, K.; Szyguła, M. Dynamic analysis of thin-walled structures as energy absorbers. Min. Mach. 2020, 2, 2-12.

30. Heyns, M.; Heyns, P. Guidelines for design of guide-roller assemblies for mining conveyances. Trans. Instr. Min. Metall. 1998, 107, A137-A145. 